\title{
El caso de aducanumab ¿Más esperanza que ciencia?
}

\section{Aducanumab's case. More hope than science?}

Eliana Sánchez-Montoya', Max Andresen² ${ }^{2}$, Raúl Corrales ${ }^{3}$, Jorge Gallardo ${ }^{4}$, Viviana Noriega ${ }^{5,7}$ Caroline R. Weinstein-Oppenheimer ${ }^{6}$

Palabras clave: aducanumab; enfermedad de Alzheimer; oligómeros $\beta$-amiloides; anticuerpo monoclonal; anticuerpos anti- $\beta$ amiloides.

Keywords: aducanumab; Alzheimer's Disease; amyloid $\beta$-oligomers; monoclonal antibodies; anti- $\beta$-amyloid antibodies.

Fecha de envío: 2021-08-20 - Fecha de aceptación: 2021-08-25

En junio del presente año, la Agencia de Alimentos y medicamentos de los Estados Unidos (FDA) otorgó aprobación mediante vía acelerada al medicamento aducanumab, desarrollado por Biogen, Inc. para tratamiento de la enfermedad de Alzheimer (EA). Esta autorización no ha estado exenta de controversia, ya que no se basó en un criterio de beneficio clínico demostrado, sino en un resultado de valoración sustituto, como es la reducción de la placa $\beta$-amieloide $(A \beta)$. Primero con mecanismo novedoso aprobado para EA desde 2003 (Jaffe, 2021).

Aducanumab es un anticuerpo monoclonal lgG1 humano, dirigido selectivamente contra oligómeros solubles y las fibrillas insolubles de $A \beta$, considerados las especies más neurotóxicas (van Dick, 2018).

El ensayo clínico de fase 1b, PRIME, en el que los participantes con EA prodrómica o leve y exploraciones con tomografías de emisión de positrones (PET) $A \beta$ positivas, que recibieron un año de infusiones intravenosas mensuales de aducanumab $(1,3,6$ o $10 \mathrm{mg} / \mathrm{kg}$ ), evidenció reducción de depósitos $A \beta$, de una manera dependiente de la dosis y el tiempo. Este estudio no tenía potencia estadística para la eficacia; sin embargo, las evaluaciones clínicas se continuaron hasta 110 semanas y mostraron ralentización de la progresión del déficit cognitivo/conductual en función de la dosis, especialmente en el ámbito funcional de la Escala de Demencia Clínica-Suma de Cajas (CDR-SB, por sus siglas en inglés), resultados que le permitieron avanzar a estudios fase 3 (Sevigny et al., 2016).

El avance de aducanumab se benefició del aprendizaje obtenido durante el desarrollo de otros anticuerpos anti $A \beta$ que quedaron en el camino; como que el mejor balance eficacia/seguridad se logra con anticuerpos con mayor selectividad por oligómeros, que contra monómeros o placa insoluble (van Dick, 2018); ya que su movilización aumenta sustancialmente el riesgo de inducir edema vasogénico y microhemorragias, por aumento del transporte amiloide. Estas anormalidades detectables en imágenes de resonancia se conocen, respectivamente, como ARIA-E y ARIA-H (Sperling et al., 2011). Esto llevó a la FDA a exigir la vigilancia trimestral, mediante imágenes de resonancia magnética (MRI) en los estudios clínicos. Ello permitió identificar que el mayor riesgo de ARI-E lo tienen los portadores del gen ApoE-ع4 (van Dick, 2018) y que en gran proporción son reversibles y asintomáticos. Como aducanumab, reconoce la fracción $\mathrm{N}$-terminal (residuos 3-6), un epítopo presente en especies agregadas de $A \beta$, pero ausente en los monómeros, pudo seguir avanzando e introdujo varias enmiendas a sus protocolos de estudio Fase 3, aumentando la denominada dosis alta desde 6 hasta $10 \mathrm{mg} / \mathrm{kg}$ (Knopman et al., 2020).

(1) Instituto de Farmacia, Facultad de Ciencias, Universidad Austral de Chile. Valdivia, Chile.

(2) Departamento de Medicina Intensiva. Facultad de Medicina Pontificia Universidad Católica de Chile. Santiago, Chile.

(3) Clínica Alemana de Santiago y Facultad de Medicina, Clínica Alemana-Universidad del Desarrollo. Santiago, Chile.

(4) Oncología Médica, Clínica Indisa. Oncología Médica, Universidad de Chile. Santiago, Chile.

(5) Oficina de Apoyo a la Investigación Clínica. Hospital Clínico Universidad de Chile y Facultad de Medicina.

(6) Escuela de Química y Farmacia y Centro de Investigación Farmacopea Chilena, Facultad de Farmacia, Universidad de Valparaíso.

Valparaíso, Chile.

(7) Facultad de Medicina. Clínica Alemana, Universidad del Desarrollo. Santiago, Chile.

Autorde Correspondencia : esanchez@uach.cl 
La fase 3 consistió en 2 estudios idénticos e independientes, denominados EMERGE y ENGAGE, de 18 meses, aleatorizados, doble ciego, controlados con placebo. El tamaño total de la muestra fue de 3285 pacientes en 348 centros, ubicados en 20 países. El criterio de inclusión fue EA temprana con rangos de evaluación en Mini-Mental State Examination, Escala de Demencia Clínica Global y Batería de Evaluación Neuropsicológica, MMSE 24-30, CDR-G 0.5, RBANS $\leq 85$, respectivamente. Los pacientes se aleatorizaron 1:1:1 en dos regímenes de dosificación con aducanumab, baja (3 mg/kg) y alta, (inicialmente $6 \mathrm{mg} / \mathrm{kg}$ y luego elevada a $10 \mathrm{mg} / \mathrm{Kg}$ ) y placebo.

Se estableció como criterio de valoración primario un cambio en la escala CDR-SB, a los 18 meses y como secundarios, cambios en otras escalas neuropsiquiátricas y los sub-estudios: PET amiloide y niveles tau-fosforilado (Tau-F) y total en líquido céfalo raquídeo (LCR), como biomarcadores relacionados con la enfermedad y la neurodegeneración.

Sorprendentemente, Biogen anuncia interrumpir sus ensayos para aducanumab en marzo de 2019, tras no superar el 20\% de diferencia comparado con placebo en su resultado primario. Sin embargo, en octubre de ese mismo año notifican un reanálisis de sus datos. Ahí, se incluyeron pacientes adicionales que habían completado las 78 semanas de tratamiento entre el corte del estudio interino y su informe negativo. En este nuevo escenario, el ensayo EMERGE mostró ahora una mejoría del 23\% para la dosis alta, en comparación con el placebo en el criterio primario. Pero ENGAGE no superó al placebo con ninguna dosis (Budd-Haeberlein et al., 2019).

En los ensayos EMERGE y ENGAGE, las imágenes de PET amiloide mostraron reducciones dependientes de la dosis, lo que está en correlación con su objetivo. EMERGE también demostró diferencias estadísticas en los niveles en LCR de Tau-F y total, mientras que ENGAGE sólo para Tau-F. También es paradójico que la dosis alta de aducanumab, en el ensayo ENGAGE, produjo un efecto similar en la Escala de Evaluación cognitiva de EA, ADAS-Cog-13, que, con la dosis baja, pero un peor efecto sobre MMSE y CDR-SOB. Estos hallazgos contradictorios, y no sometidos a escrutinio de pares evaluadores, aumentan la preocupación sobre la solidez de los efectos de aducanumab y pudieran deberse a heterogeneidad en la evolución de los pacientes.

Siendo la EA una enfermedad con alto grado de variabilidad en su progresión en los pacientes, un único estudio positivo no resulta válido para respaldar categóricamente una afirmación de eficacia. La comunidad científica abogaba por un tercer estudio Fase 3, que pudiera aportar mayor evidencia.

Con todo, la FDA ya emitió su veredicto y considera a aducanumab prometedor para lograr una reducción del declinamiento cognitivo de esta devastadora forma de demencia. Cabe señalar, que una aprobación mediante la vía acelerada no es definitiva, debiendo Biogen presentar ensayos clínicos adecuados y bien controlados para verificar y describir el beneficio clínico, en una Fase 4 de pos-comercialización. Si estos ensayos clínicos no logran verificar el beneficio clínico o no se llevan a cabo con la debida diligencia, la FDA puede retirar esta aprobación. El plazo establecido de finalización de este estudio es febrero de 2030. Los pacientes que reciban aducanumab deberán someterse estudios periódicos de imagenología, para detectar edema cerebral o sangrado. Se estima un costo anual de US \$56000, sin incluir PET y MRI, para vigilancia de eficacia y ARIA.

Biogen tiene un plazo de nueve años, en los que aducanumab tiene la oportunidad de probar la hipótesis de la cascada amiloide que no ha sido rebatida ni confirmada en 30 años (Selkoe et al., 2016), o, por el contrario, someter a pacientes esperanzados, a un tratamiento costoso, pero ineficaz, y no exento de serios efectos adversos.

\section{Referencias}

Budd-Haeberlein S, Von Hein, CTian Y, Chalkias S, Muralidharan KK. (2019). EMERGE and ENGAGE topline results: two phase 3 studies to evaluate aducanumab in patients with early Alzheimer's disease. En Clinical Trials on Alzheimer's Disease Conference (pp. 4-7).

Jaffe S. (2021). US FDA defends approval of Alzheimer's disease drug. The Lancet 398, 12.

Knopman DS, Jones DT. Greicius MD. (2021). Failure to demonstrate efficacy of aducanumab: An analysis of the EMERGE and ENGAGE trials as reported by Biogen, December 2019. Alzheimers Dement. 17, 696-701.

Selkoe DJ \& Hardy J. (2016). The amyloid hypothesis of Alzheimer's disease at 25 years. EMBO molecular medicine 8, 595-608.

Sevigny J, Chiao P, Bussière T, Weinreb PH, Williams L, Maier M. et al. (2016). The antibody aducanumab reduces $A \beta$ plaques in Alzheimer's disease. Nature 537, 50-56.

Sperling, R A, Jack, C R, Black, S E, Frosch, M. P., Greenberg, S M, Hyman, B T, ... \& Schindler, R J. (2011). Amyloid-related imaging abnormalities in amyloid-modifying therapeutic trials: recommendations from the Alzheimer's Association Research Roundtable Workgroup. Alzheimer's \& Dementia, 7(4), 367-385.

van Dyck CH. (2018). Anti-amyloid- $\beta$ monoclonal antibodies for Alzheimer's disease: pitfalls and promise. Biological Psychiatry $\mathbf{8 3}$, 311-319. 